\title{
GIS-based coastal area suitability assessment of geo-environmental factors in Laoshan district, Qingdao
}

\author{
C. Y. Ju${ }^{1}$, Y. G. Jia ${ }^{1,2}$, H. X. Shan ${ }^{1,2}$, C. W. Tang ${ }^{3}$, and W. J. Ma ${ }^{1}$ \\ ${ }^{1}$ College of Environmental Science and Engineering, Ocean University of China, Qingdao 266100, China \\ ${ }^{2}$ Key Lab. of Marine Environment \& Ecology, Ministry of Education (Ocean University of China), Qingdao 266100, China \\ ${ }^{3}$ Qingdao Geotechnical Investigation and Surveying Research Institute, Qingdao 266100, China
}

Correspondence to: Y. G. Jia (yonggang@ouc.edu.cn)

Received: 29 June 2011 - Revised: 16 November 2011 - Accepted: 17 November 2011 - Published: 17 January 2012

\begin{abstract}
With increasing urbanization, particularly in the coastal regions of developing countries, the development of disaster management schemes is needed as the losses from a single event can destroy decades of development and threaten local populations, buildings and infrastructure. Geoenvironmental suitability is often evaluated systematically in order to assess the nature of hazards and their potential damage to human life, land, buildings and other property. A suitability assessment will indicate the priorities for geological and environmental hazard management. This paper presents a geological environment suitability assessment that aims to identify grading in a current seaside urban development and develop practices to aid in the identification of hidden geological and environmental hazards. The Laoshan area in the city of Qingdao was used as a case study because it constitutes a good example of a developing city with geological and environmental threats. Also, urban plans have been drawn up here with insufficient or absent information on losses from potential natural hazards.
\end{abstract}

\section{Introduction}

An increasing proportion of the world's population is based in coastal cities because of the beneficial services they provide (McGranahan et al., 2007). However, the rapid expansion of urban areas and accelerated growth in population has resulted in increasing environmental problems, particularly geo-environmental issues that are the product of natural and human activities (Dai et al., 2001). By comparing geo-environmental factors with impact factors to assess a complex geo-environmental system, it is possible to determine whether the natural and human environments have been utilized optimally. If not, the established system can be refined and improved through the use of such tools as a geo-environmental suitability assessment.

The ultimate goal of a geo-environmental assessment is to divide the study area into homogeneous units that can show the differential suitability for engineering land use. The results of a suitability assessment can be professionally mapped to show diverse areas with different suitability levels. The differentiation among the areas is, however, attribute-specific, because the kinds of graphs used only show a relative suitability grade for certain areas compared to others and do not represent absolute values.

A geographical information system (GIS) is a powerful tool for geo-environmental evaluation in urban planning and designing. The spatial analysis power of GIS has been widely used to assess land use suitability by mapping and analysis (McHarg, 1969; Hopkins, 1977; Brail and Klosterman, 2001; Collins et al., 2001; Malczewski, 2004), and geologic hazards and vulnerability (e.g., Atkinson et al., 1998; Carrara et al., 1991; Hiscock, 1995; Dai et al., 2001). However, related studies that address geo-environmental evaluations for urban planning have been limited (Dai et al., 2001). This paper analyzes the suitability of a geo-environmental system for the coastal city of Qingdao, China, using an Analytical Hierarchy Process (AHP). There are two main aims of this paper: (i) to outline the geo-environmental characteristics of this coastal city study area and the techniques required for GIS-based geo-environmental suitability mapping, and (ii) to identify the challenges and prospects of GIS-based land-use suitability analysis in the Laoshan District of Qingdao. 


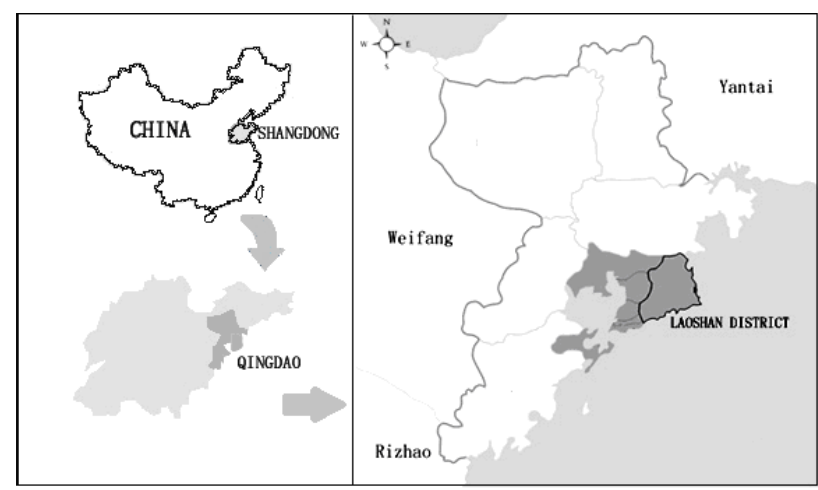

Fig. 1. Map showing the location of the city of Qingdao in China (left); the study area is the Laoshan District (right).

\section{Study area and materials}

\subsection{Study area}

The Laoshan District is located along the southeastern part of the Shandong Peninsula on the Yellow Sea coast of China, and includes four blocks (Zhonghan, Shazikou, Beizhai and Wanggezhuang). This area lies between $36^{\circ} 03^{\prime}$ and $36^{\circ} 23 \mathrm{~N}$ and $120^{\circ} 24^{\prime} 33^{\prime \prime}$ and $120^{\circ} 43^{\prime} \mathrm{E}$, covering $389.64 \mathrm{~km}^{2}$ (Fig. 1). This study deals with the geo-environmental characteristics of this region.

The Laoshan District has an extremely varied topography as a result of geological and geomorphologic processes. Most of the land area in the district is mountainous. The topography of Laoshan District is higher in the middle and lower at the edges. Mt. Laoshan, reaching an elevation of $1133 \mathrm{~m}$ above sea level, is the second highest mountain in Shandong Province after Mt. Taishan, and is the highest mountain along China's $18000 \mathrm{~km}$ long coastline. Mountain ridges are the source of several streams that are controlled mainly by topography and geomorphology.

The exposed strata of Laoshan District are Proterozoic metamorphic rocks, Mesozoic (primarily Cretaceous) clastic rocks, and loose Cenozoic (mainly Quaternary) deposits. Structural patterns are mainly aligned with NE-SW or NWSE strikes. A range of geomorphic types have formed in Laoshan District, controlled by underlying geological structures, stratal lithologies, and exogenic geological processes. The main geomorphic features are fluvial landform terraces and marine landforms; diluvial fans have developed along the river.

Groundwater distribution is strictly controlled by geological structures, stratal lithologies and landforms. Laoshan District is also a region of Quaternary accumulation, where material of varied thicknesses has accumulated on some of the ranges since the Cenozoic era (Kusky et al., 2011).

Historically, urban development has been limited primarily to lowlands or low slope areas within mountainous regions. However, in recent years, development has spread rapidly upslope and also into small narrow valleys. As a result, disasters triggered by slope instabilities caused by human activities have become increasingly common. Potential hazards are particularly apparent along mountain roads. Local experts (Jinbo et al., 2006) have proved that the probability of geohazards in mountainous areas is higher than in neighboring regions. Simultaneously, pre-existing hazards (Fig. 2), even those that had been in a dormant or intermittent state, can be destabilized by heavy rainstorms, seismic activity, other hazards (debris, rockfall and landslide) and human activities. It is obvious that impact factors arising from human activities are more of a concern in an urban development. The scarcity of stable land for urban development exposes an increasing population to geological hazard and risk.

The local geological setting of the Laoshan District has resulted in high ground stress that is stored in rock slopes giving rise to universal slope deformation in this area. Numerous landslides with the potential to develop new slope instabilities have been identified, including some in tourist areas next to a highway, that have a high level of hazard to passersby and to infrastructure lower down on the hillslope (Jinbo et al., 2006). Most of the landslides are small in scale, but a few of them are mid-sized, which suggests that these landslides cannot be ignored, particularly because records link the instigation of these slides to human activity, for example those occurring beside roads.

In recent decades, records documenting unstable slope and collapse shows that eight collapses have happened around the Laoshan District, and a total of 118 potential hazard points are mapped along roadsides in tourism areas. In the documented case, most slope collapses were triggered by excavation, but the geomorphology, lithology and structure of the rock slopes may also have contributed to the slope collapses.

Unstable slopes have been found with tensile fissures, some of which have caused damage to houses. In addition, abundant quantities of limestone have been randomly excavated around urban areas, particularly on roadsides, which has also caused unstable slopes. Such unstable slopes threaten the safety of inhabitants and passersby.

Excavation scars the natural landscape and changes the shot-period stress distribution of the slope. This sometimes gives rise to landslides, collapses and debris flows. Furthermore, excavation causes floating dust that pollutes the air, destroys vegetation, and causes water loss and soil erosion

Two debris flows have been recorded in the region, along with five potential hazard points. The initiation of debris flows is mainly caused by heavy rainfall or loosened solid materials.

\subsection{Materials}

In urban geo-environmental assessment research, the Earth's surface can be categorized based on factors related to topography, geography and other physical factors. We have used 


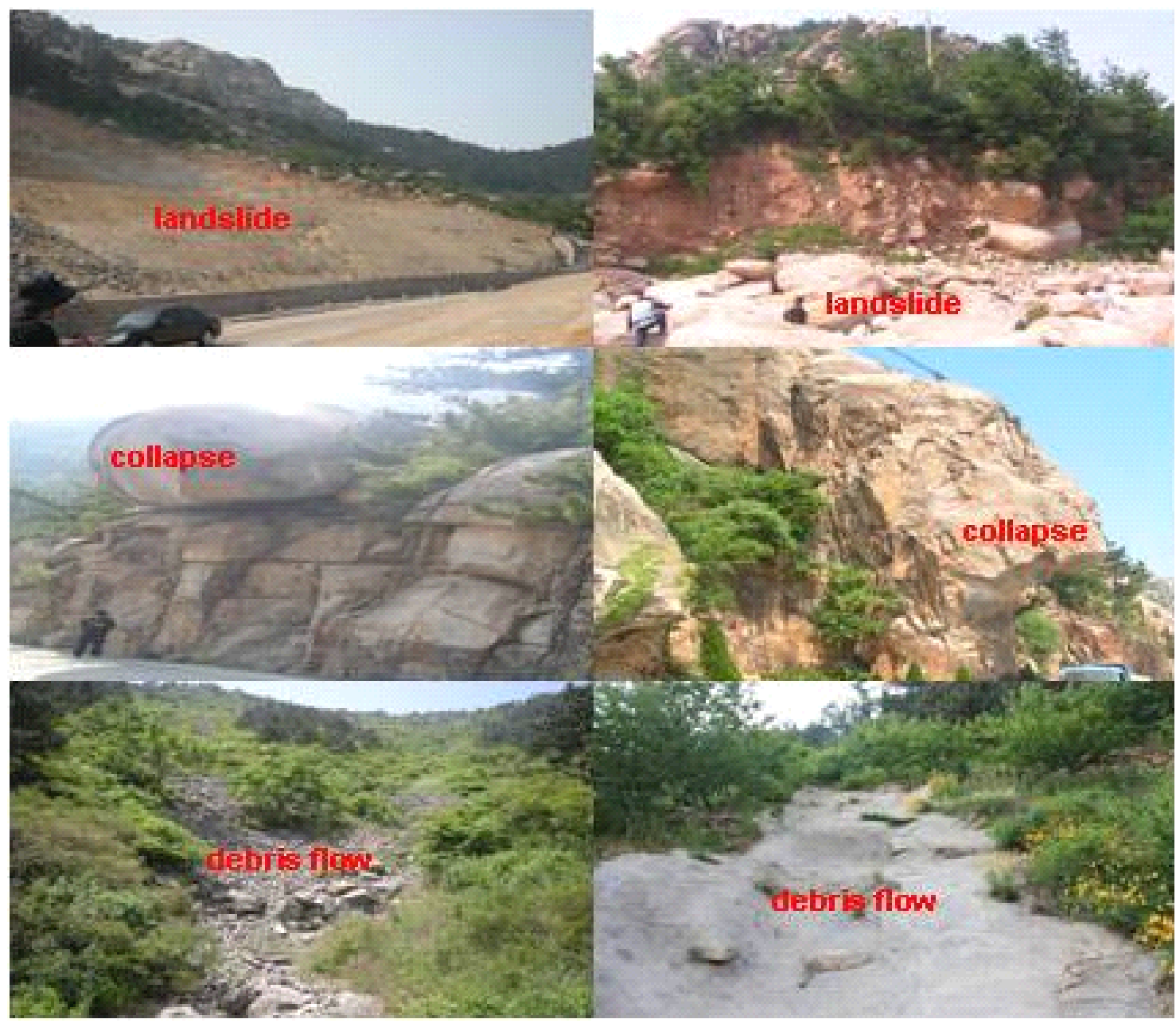

Fig. 2. Photographs of landslides, debris flows and collapse (as labeled) (Chunyan et al., 2001).

topography, geomorphology, rock and soil-type, geological structure and hydrogeology for our assessments.

Topographic and geological data and maps were collected for each category and compiled in structured spatial databases using GIS software. These databases contained vector data. Additionally, polygons corresponding to identifiable units within the urban geo-environment were extracted using geological maps produced in 1990 by the $\mathrm{Bu}-$ reau of Geology and Mineral Resources. Here, the urban geo-environment was considered to include areas defined by their geomorphology, rocks and soil, geological structure and hydrogeology. These include most of the Laoshan District covered by the study area. Topographic maps were developed from digital elevation model (DEM) data produced by professional bodies.

\section{Assessment of geo-environmental suitability}

\subsection{Methods and procedure}

\subsubsection{An overview of methods}

The analytical hierarchy process (AHP), proposed by Saaty in the early 1970s, is a comprehensive, logical and structural system, which allows a better understanding of complex decisions by decomposing the problem into a hierarchical structure (Saaty, 1977; Saaty and Vargas, 1991).

Basically, AHP involves building a hierarchy (a ranking) of decision elements, and then employing a pair-wise comparison procedure to arrive at a scale of preference among a set of alternatives. In the construction of a pair-wise comparison matrix, each factor is rated against every other factor by assigning a relative dominant same scale value. The sum of the components of the eigenvector will be unity. Thus we obtain a vector of weights, which reflects the relative 


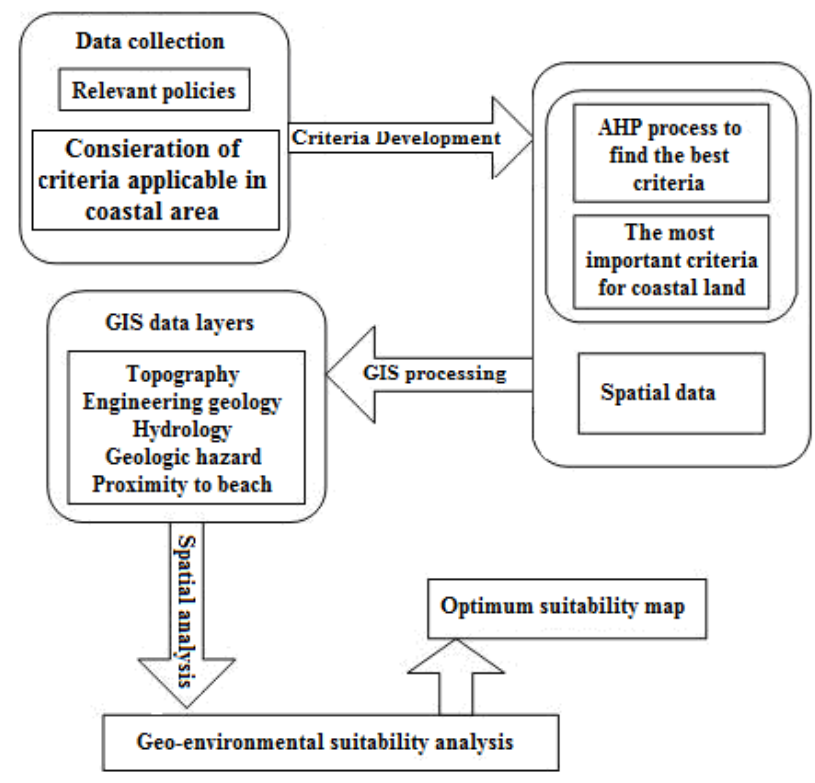

Fig. 3. Methodological framework for this study.

importance of the various factors from the matrix of paired comparisons (Dai et al., 2001).

The AHP method is based on: (1) decomposition of the decision problem, (2) comparative judgment of the elements, and (3) synthesis of the priorities. In the process of synthesis, an index of consistency known as the consistency ratio (CR) is used to indicate the likelihood that the matrix judgments were generated randomly (Saaty, 1977; Dai et al., 2001).

$\mathrm{CR}=\frac{\mathrm{CI}}{\mathrm{RI}}$

where the random index (RI) is the average of the resulting consistency index that depends on the order of the matrix given by Saaty (1977), and the consistency index (CI) can be expressed as

$\mathrm{RI}=\frac{\left(\lambda_{\max }-n\right)}{n-1}$

where $\lambda_{\max }$ is the largest or principal eigenvalue of the matrix, and $n$ is the order of the matrix. A consistency ratio (CR) on the order of 0.10 or less is reasonable (Saaty, 1977).

The introduction of cartographic modeling and map algebra techniques into computer-assisted mapping was an important advancement in the application of land-use suitability methods (Tomlin, 1990; Malczewski, 2004). Computerassisted overlay techniques, especially the spatial overlay techniques of geographic information systems (GIS) (Steinitz et al., 1976; Collins et al., 2001), are very effective for processes involving vector overlap because of their advantages in terms of time, cost, and labor consumption. GIS has been used in this study to overlap various factor maps and obtain suitable final maps faster and more efficiently.

\subsubsection{Assessment variables and procedures}

A comprehensive analysis of the primary-level physical settings within Laoshan District revealed five major geoenvironmental variables for assessment. Each of these variables or categories has a number of sub-variables at the secondary level. (1) Landscape is important because it directly affects the nature of coastal urban development and engineering activities. (2) Terrain is important for maintaining slope stability and is critical to the distribution of other localscale variables. (3) Rock type and the Quaternary deposits relate to slope stability and play major roles in construction and engineering. (4) Geological structures affect the security of engineering activities. (5) The distribution and characteristics of hydrogeological regimes in a study area determine the amount of water available for population growth and the development of infrastructure. Geologic hazards are also an important geo-environmental consideration. The geoenvironmental roles of each of these factors varies from region to region. Therefore, due to the change in dominance in different areas, the same geo-environmental factor could have dissimilar influences at a different location.

The aforementioned information was considered to be pertinent for defining the geo-environmental characteristics of the study areas (Fig. 3). The related geological factor maps were digitized using GIS software, and then a homogenous polygon was considered as a unit for any given factor. All influential factors were standardized and weighted, and then combined for each urban suitable geo-environmental category (Yan-Suil et al., 2006).

During the geo-environmental evaluation process, a most important step is to be certain of a standardized measurement system for all factors (Dai et al., 2001). The collection of basic data needs to be standardized to a uniform suitability rating scale. The value that each factor contributes to the decision is based on a set of rules that are governed by the shape of the threshold value for each factor (Table 2).

\subsection{Results of geo-environmental suitability analysis}

In this study, the first step was the analysis of geoenvironmental maps and factors from map attribute tables, where the data were converted into vector format. AHP calculates the relative weights for each determinant based on a questionnaire; these weights then are used to generate a comparison matrix (e.g., Table 3 for main criteria). Then, a GIS statistical package was used to calculate the values of factors and correlate among the affected map layers. In this process, coefficients were estimated using the maximum likelihood method. The final results are shown in Table 2.

A suitability assessment was then formed using a multiple criteria evaluation to combine and optimize a set of criteria from a specific category. In this study, factors are combined 
Table 1. Scale of preference between two elements (Saaty, 1998, 2001; Hafeez et al., 2002).

\begin{tabular}{lll}
\hline $\begin{array}{l}\text { Preference weights/ } \\
\text { level of importance }\end{array}$ & Definition & Explanation \\
\hline 1 & $\begin{array}{l}\text { Equally } \\
\text { preferred }\end{array}$ & Two activities contribute equally to the objective \\
\hline 3 & $\begin{array}{l}\text { Moderately } \\
\text { preferred }\end{array}$ & $\begin{array}{l}\text { Experience and judgment slightly favor one activity } \\
\text { over another }\end{array}$ \\
\hline 5 & $\begin{array}{l}\text { Strongly } \\
\text { preferred }\end{array}$ & $\begin{array}{l}\text { Experience and judgment strongly or essentially favor } \\
\text { one activity over another }\end{array}$ \\
\hline 7 & $\begin{array}{l}\text { Very } \\
\text { strongly } \\
\text { preferred }\end{array}$ & $\begin{array}{l}\text { An activity is strongly favored over another and its dom- } \\
\text { inance demonstrated in practice }\end{array}$ \\
\hline 9 & $\begin{array}{l}\text { Extremely } \\
\text { preferred }\end{array}$ & $\begin{array}{l}\text { The evidence favoring one activity over another is af- } \\
\text { firmed to the highest degree possible }\end{array}$ \\
\hline $2,4,6,8$ & $\begin{array}{l}\text { Intermediates } \\
\text { values }\end{array}$ & $\begin{array}{l}\text { Used to represent compromise between the preferences } \\
\text { listed above }\end{array}$ \\
\hline Reciprocals & Reciprocals for inverse comparison \\
\hline
\end{tabular}

Table 2. Evaluation of five variables and sub-variables with evaluation scores for suitability in the Laoshan District.

\begin{tabular}{|c|c|c|c|c|c|c|c|c|c|}
\hline STAGE 1 & & & STAGE 2 & & & STAGE 3 & & & STAGE 4 \\
\hline Main criteria & Weight & \multirow{32}{*}{$\begin{array}{l}* \mathrm{CR} \\
0.0827\end{array}$} & Criteria & Weight & $* \mathrm{CR}$ & Sub-criteria & Weight & $* \mathrm{CR}$ & $\sum$ Weight \\
\hline \multirow[t]{15}{*}{ Topography } & \multirow{15}{*}{0.3114} & & Slope gradient & 0.468 & 0.0043 & $\leq 5.0$ & 0.3241 & 0.0036 & 0.047232778 \\
\hline & & & & & & $5.1-15.0$ & 0.245 & & 0.035705124 \\
\hline & & & & & & $15.1-25.0$ & 0.1852 & & 0.026990159 \\
\hline & & & & & & $25.1-35.0$ & 0.1399 & & 0.020388354 \\
\hline & & & & & & $>35.0$ & 0.1058 & & 0.015418784 \\
\hline & & & Elevation & 0.1967 & & $\leq 20$ & 0.2868 & 0 & 0.017567183 \\
\hline & & & & & & $20-50$ & 0.2348 & & 0.014382059 \\
\hline & & & & & & $50-100$ & 0.1922 & & 0.011772707 \\
\hline & & & & & & $100-500$ & 0.1574 & & 0.009641125 \\
\hline & & & & & & $>500$ & 0.1288 & & 0.007889307 \\
\hline & & & Relief type & 0.3353 & & Hill & 0.2772 & 0.0011 & 0.028943123 \\
\hline & & & & & & tectonic denudation lower mountain & 0.2362 & & 0.024662214 \\
\hline & & & & & & flood plain, terrace, the edge of foothill & 0.1934 & & 0.020193362 \\
\hline & & & & & & gently sloping field & 0.1583 & & 0.016528486 \\
\hline & & & & & & coastal plain & 0.1349 & & 0.014085235 \\
\hline \multirow[t]{5}{*}{ Engineering geology } & \multirow[t]{5}{*}{0.3241} & & & & & Type of hard intrusive rocks & 0.2576 & 0.0039 & 0.08348816 \\
\hline & & & & & & Type of hard and semi hard rocks & 0.2284 & & 0.07402444 \\
\hline & & & & & & type of semi hard rocks & 0.1531 & & 0.04961971 \\
\hline & & & & & & Type of Intermontane valley loose (soft) & 0.2195 & & 0.07113995 \\
\hline & & & & & & Coastal soft (loose) & 0.1414 & & 0.04582774 \\
\hline \multirow[t]{3}{*}{ Hydrological geology } & \multirow[t]{3}{*}{0.1146} & & & & & Bedrock fissure water & 0.3333 & 0 & 0.03819618 \\
\hline & & & & & & Loose rock pore water & 0.3333 & & 0.03819618 \\
\hline & & & & & & Clastic rock pore and fissure water & 0.3333 & & 0.03819618 \\
\hline \multirow[t]{5}{*}{ Geologic hazard } & \multirow[t]{5}{*}{0.1399} & & Area of occurrence probability & & & No & 0.2868 & 0 & 0.04012332 \\
\hline & & & & & & Hardly & 0.2348 & & 0.03284852 \\
\hline & & & & & & Low & 0.1922 & & 0.02688878 \\
\hline & & & & & & Middle & 0.1574 & & 0.02202026 \\
\hline & & & & & & High & 0.1289 & & 0.01803311 \\
\hline \multirow[t]{3}{*}{ Proximity to beach } & \multirow[t]{3}{*}{0.1101} & & distance from beach $(\mathrm{m})$ & & & $0-500$ & 0.2506 & 0.0171 & 0.02759106 \\
\hline & & & & & & $500-1000 \mathrm{~m}$ & 0.3498 & & 0.03851298 \\
\hline & & & & & & $>1000 \mathrm{~m}$ & 0.3996 & & 0.04399596 \\
\hline
\end{tabular}


Table 3. Comparison matrix for main criteria.

\begin{tabular}{llllll}
\hline & Topography & $\begin{array}{l}\text { Engineering } \\
\text { geology }\end{array}$ & $\begin{array}{l}\text { Hydrological } \\
\text { geology }\end{array}$ & $\begin{array}{l}\text { Geologic } \\
\text { hazard }\end{array}$ & $\begin{array}{l}\text { Proximity } \\
\text { to beach }\end{array}$ \\
\hline Topography & 1 & 5 & 5 & 5 & 3 \\
\hline Engineering geology & $1 / 5$ & 1 & 8 & 7 & 7 \\
Hydrological geology & $1 / 5$ & $1 / 8$ & 1 & 1 & 1 \\
Geologic hazard & $1 / 5$ & $1 / 7$ & 1 & 1 & 5 \\
Proximity to beach & $1 / 3$ & $1 / 7$ & 1 & $1 / 5$ & 1 \\
\hline
\end{tabular}

$\mathrm{CR}=0.827$

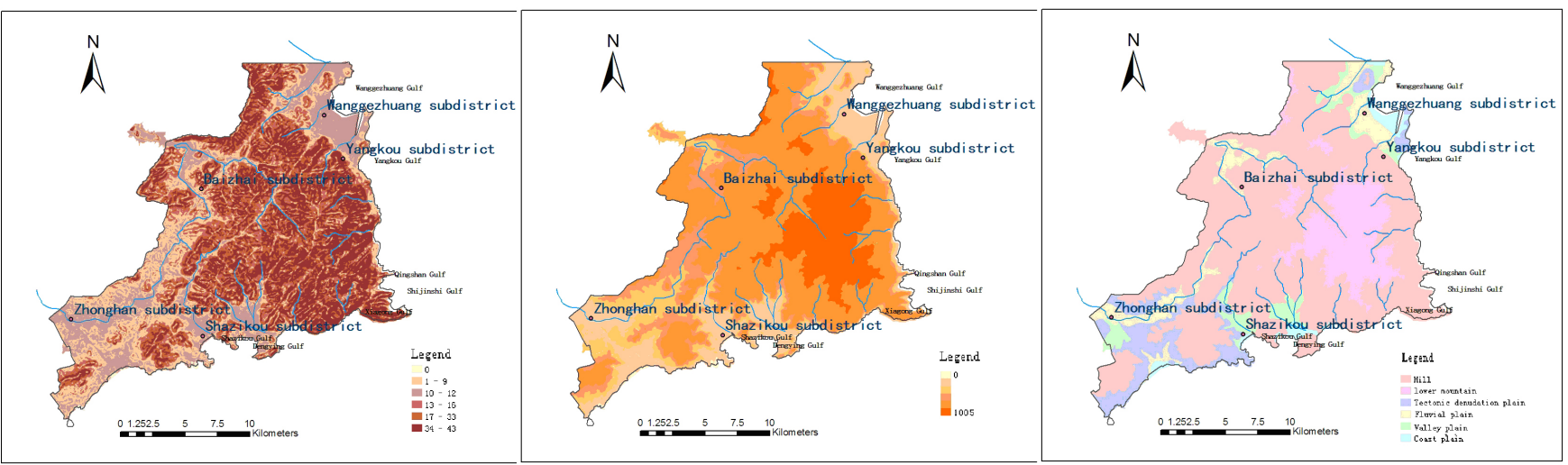

Fig. 4. Landform maps. (a): slope map; (b): elevation map; (c): relief map.

in weighted linear combinations (Easstman et al., 1995; Dai et al., 2001), i.e.,

$S=\sum w_{i} x_{i}$

where $S$ is the suitability, $i$ is the sub-criteria factor reclassified from main criteria, $w_{i}$ is the main criteria weight of $i$, and $x_{i}$ is the sub-criteria weight of $i$.

The data layer corresponding to the factors that affect suitability were assigned weight values through ArcGIS, and a weighted linear combination for each category was created along with a suitability assessment with a value range that was standardized from the factor maps. For the suitability assessment, an equal interval classification scheme running between the minimum and the maximum values was employed. The resultant vector maps are displayed in Fig. 6.

In Fig. 4 , note that the high slopes of the mountainous areas are partitioned into different zones. The valleys and gullies have the largest suitability scores. The low-mountain zone was the second most common inside the study area, with a marginally higher area than the hillside and terrace zones. The foothills had a moderate suitability score, but were the most dominant landform; the coastal region was the tiniest. There was an obvious altitudinal stratification of landforms over the wide range of elevation. Associated with the distribution were distinct patterns in slope. The zone be- tween $5.1^{\circ}$ and $15.0^{\circ}$ was the most extensive, and flat regions were the rarest.

Hard intrusive rocks are distributed widely on most land and coastal soft soils dominate along the littoral belt (Fig. 5a). Bedrock fissure water was the most extensive in the hydrologic geology map (Fig. 5b); pore and fissure water in clastic rock was minimal in the study area. The geological hazard map (Fig. 5c) mainly displays the potential hazard areas along rivers. Most hazardous areas were affected by the slope and basin in the ma Proximity to beach map (Fig. 5d) shows an increasing hazard closer to the coast.

By following the above data process, a geo-environmental suitability assessment was assembled. Fig. 6 shows suitability from high (dark brown) to low (light yellow). Topography is the most important factor in the suitability assessment, so it follows that the distribution of suitability grade varies with topography. Note that wide valleys and gullies have the largest suitability score near rivers in the western part of the study area (dark brown or brown), whereas steep slope areas are avoided. The foothills, hillsides and terraces all have a moderate suitability score and are larger than other areas.

The southeast coastal area has a lower suitability than other areas due to the local geology, which is unsuitable for urban development, even though the construction of seaside dwellings here is popular. Field checks confirmed that the 


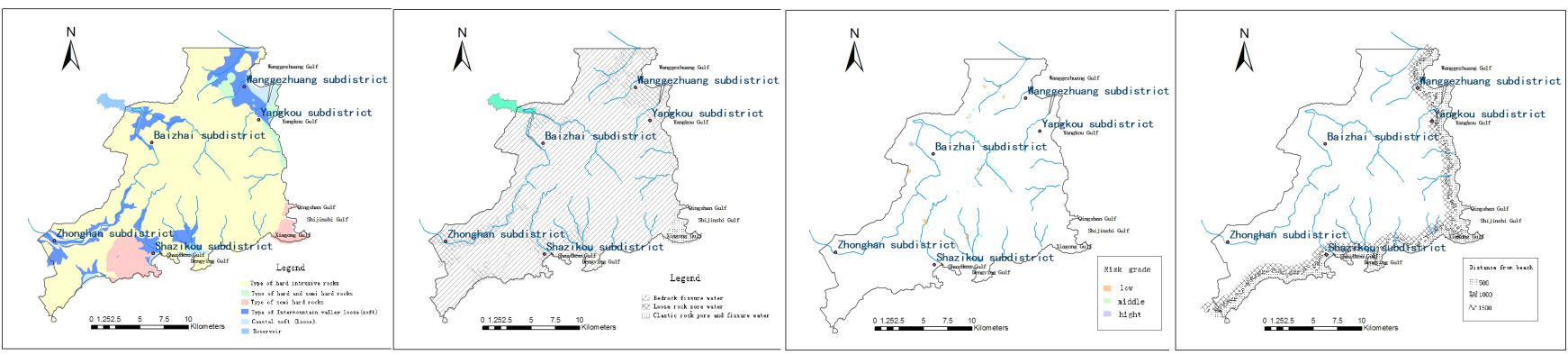

Fig. 5. Engineering geology map (a); hydrological geology map (b); Geologic hazard map (c); Proximity to beach map (d).

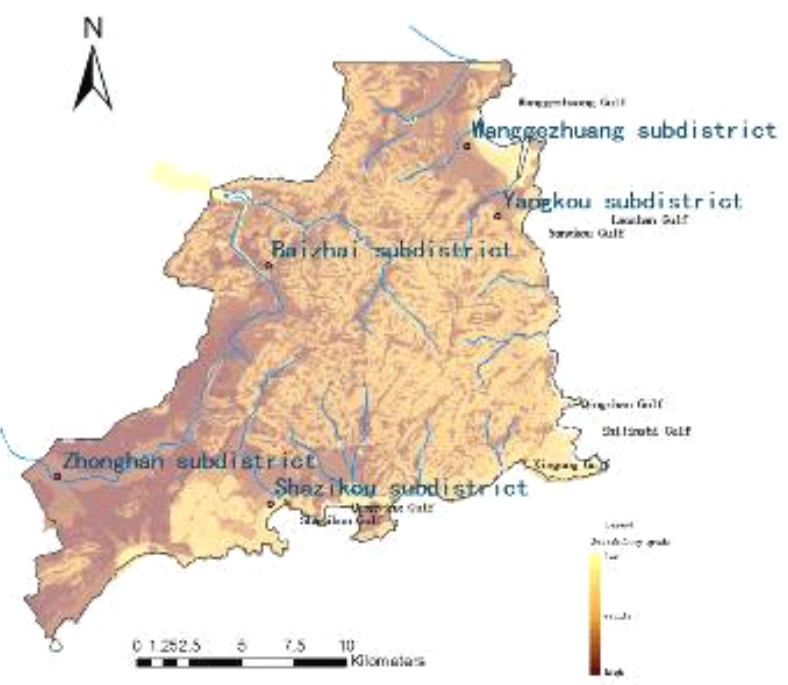

Fig. 6. Geo-environmental suitability assessment.

results are consistent with the actual environment.

\section{Discussion}

To maximize the beneficial use of land in the Laoshan District (or any region, for that matter), actual geoenvironmental conditions should be taken into consideration at all stages of urban planning. This study is underpinned by data analysis, using the AHP approach and GIS software right from the initial planning process. In this research, the AHP approach was applied to find an optimal geo-environmental weighting for coastal land use. GIS software was used to collate vector data from a variety of source materials. The vector layers in the analysis produced natural boundaries for various attributes that would have been difficult to determine using usual methods of gridding data. Furthermore, the method contained the integrality of the same attributed source data. Evaluation of the input factors resulted in the development of an optimal suitability plan for sustainable coastal land use. In particular, the factors selected and data analysis method introduced in this study have impacted and revised our understanding of coastal Laoshan. The same methods can be applied to other coastal areas. This scheme encourages understanding of the geological conditions in an area and allows regional planners to make timely decisions more accurately. Such spatial analysis techniques enable the development of a more effective suitability assessment. In particular, using spatial geo-environmental data for suitability analyses of sustainable coastal land use development is important. However, the selection of proper and optimal factors for the suitability assessment is also very important.

This research requires large amounts of reliable data in the analysis process. Errors in the data may have the ability to change the results of the suitability assessment and lead to incorrect proposals for planning. In general, though, the more detailed informational layers there are in the assessment, the more accurate the resulting analysis will be. However, excessive layer data may sometimes result in error or bias as a consequence of interinhibitive factors. So adapting numbers and types of layer data are basic components of any suitability assessment.

\section{Conclusions}

This study successfully identified geo-environmental suitability factors of a coastal area, and efficiently produced a suitability analysis for coastal zone development utilizing a scientific approach to spatial land area distribution planning. The aim was to find the optimal factors that affect the assessment of geo-environmental suitability while maintaining good environmental conditions. Relative factors were selected to test coastal zone suitability using spatial data that were collected by a number of methods. These factors were used to prepare a local plan for the Laoshan District in Qingdao. It developed innovative, scientificallybased factors to characterize the geo-environmental suitability for future sustainable development along the coast of this district. The integration of relative geo-environmental factors provided a spatial approach to the efficient planning of future, coastal land use development. In addition, the geo-environmental suitability assessment processes can be 
enhanced by considering allocations and simulations using new methods and techniques.

Acknowledgements. This study was supported by the National Natural Science Foundation of China (Contract Nos. 40876042 and 41072215) and the National High Technology Research and Development Program of China (863 Program) (Contract No. 2008AA09Z109). The authors are grateful to all members for their help in the experiments. We also thank two anonymous reviewers for their valuable comments.

Edited by: F. Luino

Reviewed by: Y. Chang and another anonymous referee

\section{References}

Atkinson, M. and Massari, R.: Generalized linear modeling of susceptibility to landsliding in the Central Apennines, Italy, Comput Geosci., 24, 373-385, 1998.

Brail, R. K. and Klosterman, R. E.: Planning Support Systems, ESRI Press, Redlands, CA, 2001.

Carrara, A., Cardinali, M., Detti, R., Guzzetti, F., Pasqui, V., and Reichenbach, GIS techniques and statistical model in evaluating landslide hazard, Earth Surf. Proc. Land., 16, 427-445, 1991.

Chunyan J., Yonggang J., Hongxian S., Changwei T., Fanghui J., Zhongnian Y.: Coastal urban road geo-disaster monitoring problems of Laoshan District, Procedia Eng. , 21, 368-375, 2011.

Collins, M. G., Steiner, F. R., and Rushman, M. J.: Land-use suitability analysis in the United States: historical development and promising technological achievements, Environ. Manage., 28 (5), 611-621, 2001.

Dai, F. C., Lee, C. F., and Zhang, X. H.: GIS-based geoenvironmental evaluation for urban land-use planning: a case study, Eng. Geol., 61, 257-271, 2001.

Hafeez, K., Zhang, Y., Malak, N.: Determining key capabilities of a firm using analytical hierarchy process, Int. J. Prod. Econ., 76, 39-51, 2002.

Heywood, I., Oliver, J., and Tomlinson, S.: Building an exploratory multi-criteria modelling environment for spatial decision support. Innovations in GIS, Taylor \& Francis, London, 127-136, 1995

Hiscock, K. M., Lovett, A. A., Brainard, J. S., and Parfitt, J.: Groundwater vulnerability assessment: two case studies using GIS methology, Quart. J. Eng. Geol., The Geological Society, 28, 179-194, 1995.

Hopkins, L.: Methods for generating land suitability maps: a comparative evaluation, Journal for American Institute of Planners, 34, 19-29, 1977.

Jinbo, M., Liang, G., Yan, L., and Hongtao, S.: Laoshan shengtai yu baohu, Shandong university press, Shandong, 2006 (in Chinese).

Kai, X., Chunfang, K., Jiangfeng, L., Liqin, Z., and Chonglong, W.: Suitability evaluation of urban construction land based on geoenvironmental factors of Hangzhou, China, Comput. Geosci., 37(8), 992-1002, 2011.
Kusky, T., Timothy K., Liang G., Shibao X., Xiaoyu G., Xingyong X.: A critical examination of evidence for a Quaternary glaciation in Mt. Laoshan, Eastern China, J. Asian Earth Sci., 40, 403 416, 2011.

Malczewski, J.: On use of weighted liner combination method in raster GIS: common and best practice approaches, Transactions in GIS, 4(1), 5-22, 2000.

Malczewski, J.: GIS-based land-use suitability analysis: a critical Overview, Prog. Plann., 6, 3-65, 2004.

McGranahan, G., Balk, D., and Anderson, B.: The rising tide: assessing the risks of climate change and human settlements in low elevation coastal zones, Environ. Urban.,19, 17-37, 2007.

McHarg, I. L.: Design With Nature, Wiley, New York, 1969.

Park, S., Soyoung P., Seongwoo J., Shinyup K., and Chuluong: Prediction and comparison of urban growth by land suitability index mapping using GIS and RS in South Korea, Landscape Urban Plan., 99, 104-114, 2011.

Pourebrahim, S., Hadipour, M., and Bin Mokhtar, M.: Integration of spatial suitability analysis for land use planning in coastal areas; case of Kuala Langat District, Selangor, Malaysia, Landscape Urban Plan., 101(1), 84-97, 2011.

Saaty, T. L.: A scaling method for priorities in hierarchical structures, J. Math. Psychol., 15, 234-281, 1977.

Saaty, T. L.: The Analytic Hierarchy Process, McGraw-Hill, New York, USA, 287, 1980.

Saaty, T. L.: The analytic hierarchy process: a 1993 overview, Cent. Europ. J. Oper. Res. Econom., 2, 119-137, 1993.

Saaty, T. L. and Vargas, L. G.: Prediction, Projection and Forecasting: Applications of the Analytic Hierarchy Process in Economics, Finance, Politics, Games and Sports, Kluwer Academic Publishers, Boston, 251, 1991.

Saaty, T. L. and Vargas, L.: Methods, Concepts and Applications of the Analytic Hierarchy Process, Kluwer Academic Publishers, Boston, 2001.

Shi, Y. W.: Urban land-use suitability assessment: a case study of Anshan city, China, Chinese Journal of Land Science Chinese Society for Land Science, 7, 28-32, 1993 (in Chinese).

Steinitz, C., Parker, P., and Jordan, L: Hand drawn overlays: their history and prospective uses, Landscape Archit., 9, 444-455, 1976.

Tomlin, C. D.: Geographical Information Systems and Cartographic Modeling, Prentice-Hall, Englewood Cliffs, NJ, 1990.

Yan-Suil, L., Jie-Yongl, W., and Li-Ying, G.: GIS-Based Assessment of Land Suitability for Optimal Allocation in the Qinling Mountains-China, Pedosphere, 16, 579-586, 2006.

Wu, Q., Qiang W., Siyuan Y., Xiong W., and Peipei C.: Risk assessment of earth fractures by constructing an intrinsic vulnerability map, a specific vulnerability map, and a hazard map, using Yuci City, Shanxi, China as an example, Environ. Geol., 46, 106, 2004. 